\title{
Effect of Roll and Rolling Temperatures on Sticking Behavior of Ferritic Stainless Steels
}

\author{
Won JIN, Jeom-Yong CHOI and Yun-Yong LEE
}

Stainless Steel Research Team, Technical Research Laboratories, Pohang Iron \& Steel Co., Ltd., Pohang P.O. Box 36, 1, Koedong-dong, Pohang-shi, Kyungbuk, Korea. E-mail: pc543552@smail.posco.kr

(Received on December 5, 1997; accepted in final form on February 23, 1998)

\begin{abstract}
The sticking behavior of several austenitic and ferritic stainless steels under the hot rolling conditions was examined in detail using a two disk type hot rolling simulator. The sticking of bare metal to roll surfaces was strongly dependent on the high temperature tensile strength and the oxidation resistance of the stainless steel. A steel having higher tensile strength and lower oxidation resistance exhibited better resistance against sticking. The sticking occurred in increasing severity in the order of $430 \mathrm{~J} 1 \mathrm{~L}, 436 \mathrm{~L}, 430$ and $409 \mathrm{~L}$. It was clarified that a high speed steel (HSS) roll was more beneficial to prevent sticking compared to a $\mathrm{Hi}-\mathrm{Cr}$ roll.
\end{abstract}

KEY WORDS: ferritic stainless steel; sticking behavior; hot rolling; high speed steel roll; high chromium roll.

\section{Introduction}

The sticking phenomenon occurs frequently during the hot rolling of ferritic stainless steels, causing surface defects on the mill product and scoring on the roll surface. The sticking of the bare metal, exposed by scale breakaway during hot rolling, to the roll surface is affected by both hot rolling conditions and the stainless steel properties. ${ }^{1-3)}$ According to previous research on sticking behavior under various rolling conditions, the sticking increases with the increasing contact stress and slip ratio, and is considered to occur in the backward slip region in the arc of contact. ${ }^{1,4)}$ In addition to the rolling condition, there is a significant difference in the sticking resistance of commercial roll materials for hot rolling. This implies that the sticking occurrence is highly dependent on the wear, scratch resistance and mechanical properties of the roll material. On the other hand, it is known that the 400 series stainless steel is more sensitive to sticking than the 300 series and also that there is a wide variation in sticking resistance among the ferritic stainless steels. ${ }^{5)}$ However, despite numerous studies, sticking prevention is still a problem in hot rolling of high Cr ferritic stainless steels.

This study employed a sticking simulator in order to investigate the effects of hot rolling temperatures and high temperature mechanical properties of roll and rolling material on the sticking behavior. Changes in sticking weight were investigated with rolling temperatures, number of roll revolutions and rolling materials. Also, in order to verify the relationship between the sticking tendency and the high temperature properties of stainless steels, high temperature tensile strength and oxidation resistance of the 300 and the 400 series stainless steels were measured.

\section{Experiments}

A sticking simulator was used to investigate the effect of hot rolling conditions on sticking behavior. Figure 1 shows the schematic diagram of the sticking simulator. The simulation was carried out by using a two disk type hot rolling simulator which consisted of a high frequency induction heater, water cooling and temperature measuring system, equipped with a contact loading system between the roll and the mating material. The experimental conditions of sticking simulation are given in Table 1. In order to simulate hot rolling process a new mating material must be used in every revolution. But, in this test, a mating material was changed after every 20 revolution test. For example, 5 new mating materials were used to simulate 100 revolution test. The sticking weight was estimated as the difference between the initial roll weight and that obtained after simulation.

The chemical compositions of steels used in this study

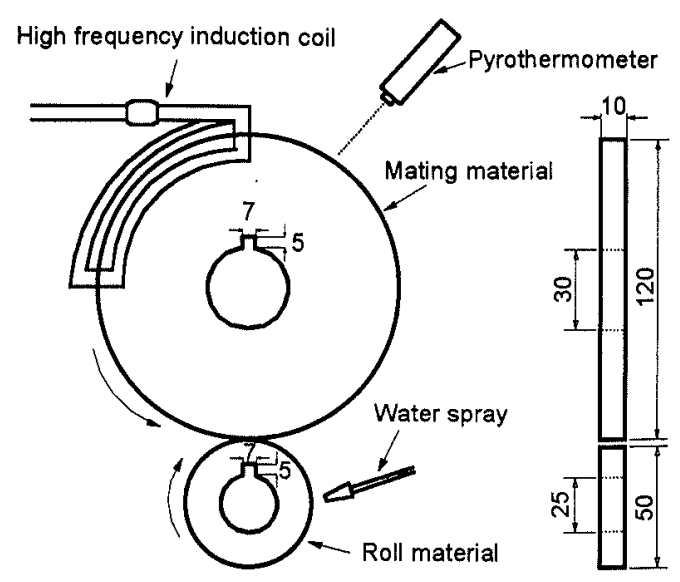

Fig. 1. Schematic diagram of the sticking simulator. 
Table 1. Experimental variables and conditions

\begin{tabular}{|c|c|c|}
\hline & Variables & Condition \\
\hline 1 & Roll material & $\mathrm{HSS}, \mathrm{Hi}-\mathrm{Cr}$ \\
\hline 2 & Mating material & $\begin{array}{c}430 \mathrm{J1L}, 436 \mathrm{~L}, 430, \\
409 \mathrm{~L}, 304\end{array}$ \\
\hline 3 & Contact stress & $400 \mathrm{MPa}$ \\
\hline 4 & Simulation temperature & $700 \sim 1000^{\circ} \mathrm{C}$ \\
\hline 5 & Number of revolutions & $5 \sim 100 \mathrm{rev}$. \\
\hline 6 & Backward slip ratio & $34 \%$ \\
\hline 7 & Rolling speed & $0.3 \mathrm{~m} / \mathrm{sec}$ \\
\hline 8 & Roughness of roll(Ra) & $1.0 \sim 2.0 \mu \mathrm{m}$ \\
\hline
\end{tabular}

Table 2. Chemical compositions of steels used.

\begin{tabular}{|c|c|c|c|c|c|}
\hline specimen & $\mathrm{Cr}$ & $\mathrm{Ni}$ & $\mathrm{Mo}$ & $\mathrm{C}$ & $\mathrm{Nb}$ \\
\hline $430 \mathrm{~J} 1 \mathrm{~L}$ & 19.1 & 0.12 & - & 0.010 & 0.30 \\
\hline $436 \mathrm{~L}$ & 18.7 & 0.01 & 0.96 & 0.021 & 0.26 \\
\hline 430 & 16.3 & 0.08 & 0.01 & 0.060 & - \\
\hline $409 \mathrm{~L}$ & 11.4 & 0.07 & - & 0.045 & - \\
\hline 304 & 18.2 & 8.30 & - & 0.050 & - \\
\hline
\end{tabular}

Table 3. Chemical compositions of roll materials used

\begin{tabular}{|c|c|c|c|c|c|c|c|}
\hline & $\mathrm{C}$ & $\mathrm{Si}$ & $\mathrm{Mn}$ & $\mathrm{Ni}$ & $\mathrm{Cr}$ & $\mathrm{Mo}$ & $\mathrm{V}$ \\
\hline HSS & 2.0 & 1.0 & 1.0 & 1.0 & 5.0 & 2.5 & 4.0 \\
\hline $\mathrm{Hi}-\mathrm{Cr}$ & 2.9 & 0.7 & 1.0 & 1.0 & 18.0 & 1.4 & 0.2 \\
\hline
\end{tabular}

are shown in Table 2. The five steels consisted of four ferritic stainless steels with various $\mathrm{Cr}$ weight percent from 11 to $19 \%$ and one austenitic steel as a reference. Also the chemical compositions of the roll materials is shown in Table 3. High temperature tensile tests were performed using a Gleeble 1500. In order to measure high temperature tensile strength, specimens were heated at $20^{\circ} \mathrm{C} / \mathrm{sec}$ and held at the desired temperature for $5 \mathrm{~min}$, then tensile tested at a strain rate of $0.3 / \mathrm{min}$. The thickness of scale layer formed at various temperatures were measured by optical microscope. The specimens were heated in the sticking simulator with a high frequency induction heater, at a heating rate $10^{\circ} \mathrm{C} / \mathrm{sec}$ with a holding time of $20 \mathrm{sec}$ at the desired temperature.

\section{Results and Discussion}

\subsection{The Effect of Roll Revolution Number}

In order to investigate the effect of the number of roll revolutions and roll materials on the sticking behavior of austenitic and ferritic stainless steels, the sticking simulation was carried out. Figures 2 and 3 show the change of sticking weight on High Chromium ( $\mathrm{Hi}-\mathrm{Cr}$ ) and High Speed Steel (HSS) rolls with number of roll revolutions at $900^{\circ} \mathrm{C}$. The sticking weight drastically increased from the first to the 20th revolution, however, subsequently, a slight decrease was noted in most steels. In the case of $409 \mathrm{~L}$, the sticking weight increased gradually. The sticking tendency in this simulation corresponds well to Kato's results ${ }^{2)}$ where sticking occurs immediately if the specific conditions of occurrence are satisfied. Accordingly, it is thought that nucleation and growth processes of sticking particles occur in the range between the 1st and the 20th revolution, but after the

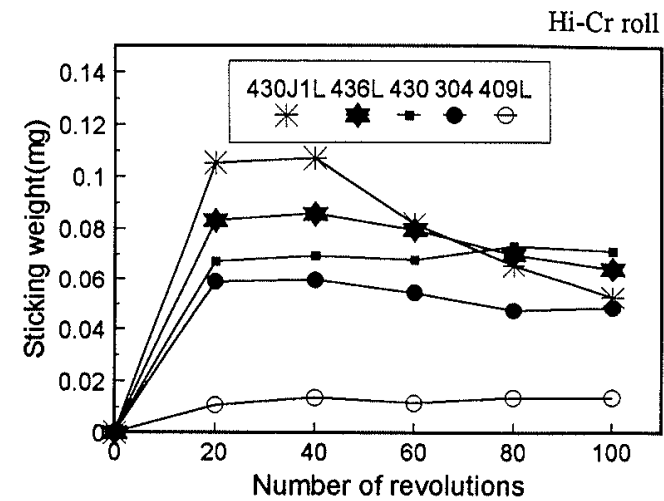

Fig. 2. Changes of the sticking weight on $\mathrm{Hi}-\mathrm{Cr}$ roll with the number of revolutions at $900^{\circ} \mathrm{C}$.

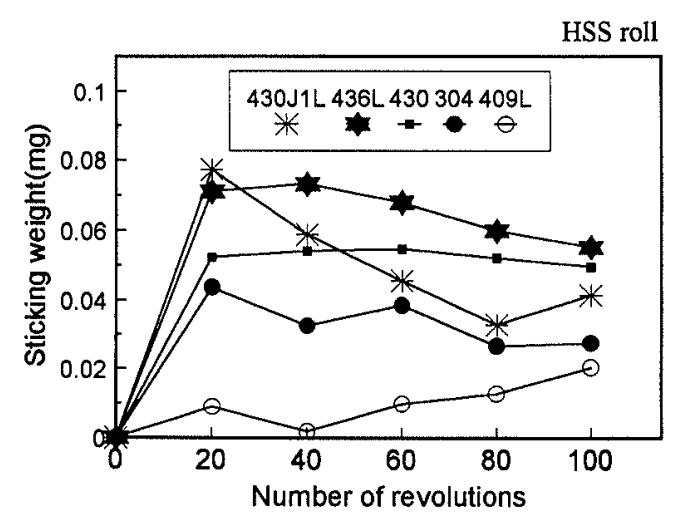

Fig. 3. Changes of the sticking weight on HSS roll with the number of revolutions at $900^{\circ} \mathrm{C}$.

20th, nucleation and growth processes of sticking particles and the separation process of these particles from the roll surface operate parallel with each other.

These results also demonstrated that the sticking occurred with increasing severity in the order of $430 \mathrm{~J} 1 \mathrm{~L}$, 436L, 430, 304 and 409L. A HSS roll was less prone to sticking than a $\mathrm{Hi}-\mathrm{Cr}$ roll. Figure 4 shows a comparison of the sticking weight changes for 430 on the $\mathrm{Hi}-\mathrm{Cr}$ and HSS rolls from the 1st to 30 th revolution. It was found that the sticking weight of the HSS was higher than that of the Hi-Cr roll between the 1st and 7th revolution, but after the 10th revolution, the situation was reversed, and the saturation of sticking weight of HSS roll reached before 10th revolution, but $\mathrm{Hi}-\mathrm{Cr}$ roll requires 20th revolution, double of the HSS roll.

The sticking behavior in the initial stages between the 1 st and 7 th revolutions was examined by scanning electron microscopy. Figure 5 shows the scanning electron micrographs of $430 \mathrm{~J} 1 \mathrm{~L}$ particles stuck on the $\mathrm{Hi}-\mathrm{Cr}$ and HSS roll surfaces after the 7th revolution. The arrows on the SEM images indicate the $430 \mathrm{~J} 1 \mathrm{~L}$ particles stuck on the roll surface. The number of particles on the $\mathrm{Hi}-\mathrm{Cr}$ roll surface was greater than on the HSS roll surface, and the particle size on the $\mathrm{Hi}-\mathrm{Cr}$ roll surface was smaller than the HSS roll. These results show clearly that the $\mathrm{Hi}-\mathrm{Cr}$ roll has more nucleation sites of sticking particles per unit area than the HSS roll. Although HSS rolls have relatively smaller number of nucleation sites, the sticking weight of the HSS roll is greater than that of the $\mathrm{Hi}-\mathrm{Cr}$ roll during the initial stage up to the 10th 


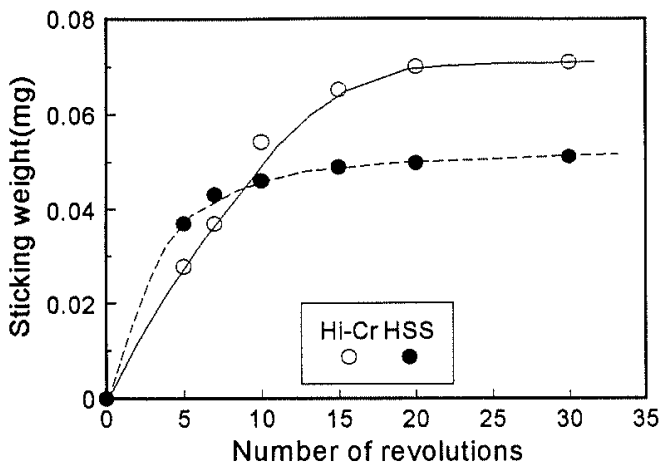

Fig. 4. Changes of the sticking weight of 430 on $\mathrm{Hi}-\mathrm{Cr}$ and HSS rolls with the number of revolutions at $900^{\circ} \mathrm{C}$.

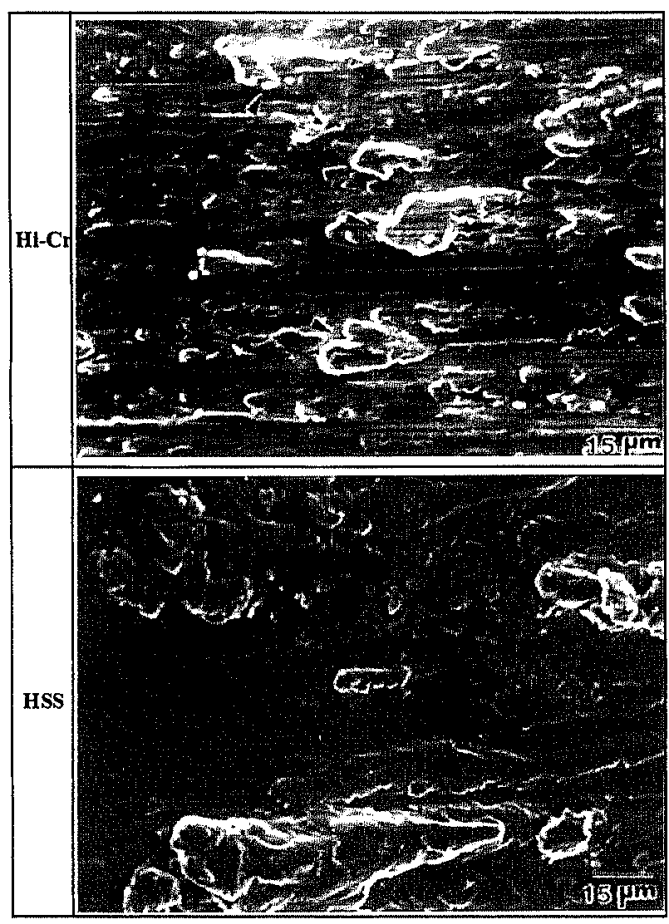

Fig. 5. SEM images showing the surface of $\mathrm{Hi}-\mathrm{Cr}$ and HSS roll after sticking simulation of $430 \mathrm{~J} 1 \mathrm{~L}$ stainless steels.

revolution because of the relatively larger particle size. But the sticking weight of the HSS roll becomes smaller than that of the $\mathrm{Hi}-\mathrm{Cr}$ roll after the 10th revolution because of the separation process of the particles which is enough to separate from roll surface. On the contrary, the particles stuck on $\mathrm{Hi}-\mathrm{Cr}$ roll did not become large during the initial stage because the particles generated at many nucleation sites grow competitively with each other. Even after the 10th revolution, small particles stuck on $\mathrm{Hi}-\mathrm{Cr}$ roll gradually grow to a critical size to separate from the roll surface. In consequence, the sticking weight of the $\mathrm{Hi}-\mathrm{Cr}$ roll is larger than that of the HSS roll after the 10 th revolution.

It is well known that the sticking weight is dependent on the roughness of roll surface and on the volume percent of the carbide. ${ }^{5)}$ Also, from the above results there is a difference in the number of nucleation sites of sticking particles between $\mathrm{Hi}-\mathrm{Cr}$ and HSS rolls, and it is necessary to understand the nature of nucleation sites on the roll surface. Figure 6 shows optical micrographs

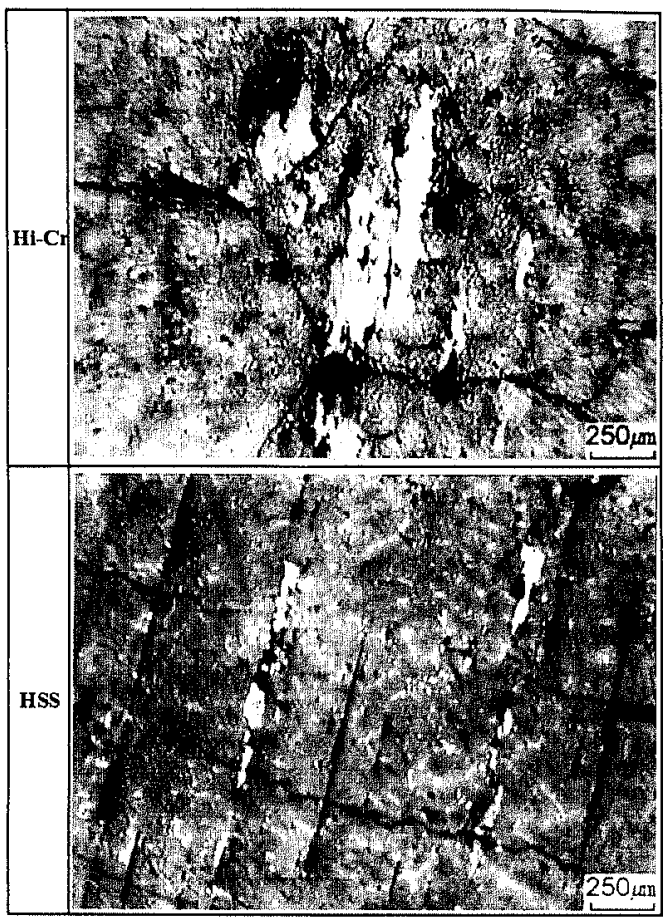

Fig. 6. Optical nicrographs showing the surface of the $\mathrm{Hi}-\mathrm{Cr}$ and HSS rolls after hot rolling of $430 \mathrm{~J} 1 \mathrm{~L}$ stainless steels.

Table 4. Mechanical properties and microstructures of HSS and $\mathrm{Hi}-\mathrm{Cr}$ roll.

\begin{tabular}{|c|c|c|}
\hline Properties & HSS roll & Hi-Cr roll \\
\hline Microstructure & $\begin{array}{c}\text { Carbide(MC }+ \\
\mathrm{M}_{7} \mathrm{C}_{3}+\mathrm{M}_{6} \mathrm{C}, \\
12 \%) \\
+ \text { Martensite }\end{array}$ & $\begin{array}{c}\left.\mathrm{Carbide}_{3}, 26.5 \%\right)+ \\
\text { Martensite }\end{array}$ \\
\hline $\begin{array}{c}\text { Total } \\
\text { hardness(Hv) }\end{array}$ & 702 & 558 \\
\hline $\begin{array}{c}\text { Hardness of } \\
\text { matrix(Hv) }\end{array}$ & 650 & 450 \\
\hline $\begin{array}{c}\text { Tensile strength } \\
\text { (MPa) }\end{array}$ & 960 & 850 \\
\hline $\begin{array}{c}\text { Resistance to } \\
\text { heat- } \\
\text { cycled fatigue }\end{array}$ & excellent & fair \\
\hline $\begin{array}{c}\text { Resistance to } \\
\text { abrasion }\end{array}$ & excellent & fair \\
\hline
\end{tabular}

of HSS and Hi-Cr commercial roll surfaces after hot rolling of $430 \mathrm{~J} 1 \mathrm{~L}$ stainless steel. These photographs show that many scratches exist on the surfaces of both $\mathrm{Hi}-\mathrm{Cr}$ and HSS rolls. The $\mathrm{Hi}-\mathrm{Cr}$ roll displays broad lath type scratches, but HSS roll has a long needle type form. White particles transferred from the stainless steel strip during hot rolling are always found on the roll surface scratches, particularly on the relatively broad scratches. This results indicate that the nucleation site of the sticking particle is a scratch on the roll surface. In addition, the significant difference in number of nucleation sites of sticking particles between $\mathrm{Hi}-\mathrm{Cr}$ and HSS roll is attributed to the disparate mechanical properties between the Hi-Cr and HSS roll. Table 4 gives the mechanical properties and the micro-structures of the HSS and $\mathrm{Hi}-\mathrm{Cr}$ rolls. ${ }^{6)}$ The resistance to abrasion and heat cycled fatigue of the HSS roll are superior to those of the $\mathrm{Hi}-\mathrm{Cr}$ roll because the hardness of the HSS roll is higher than that 


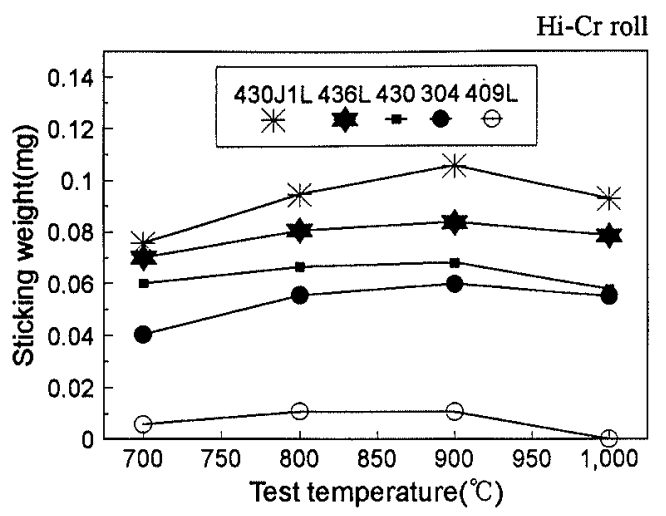

Fig. 7. The effect of temperatures on the changes of the sticking weight on $\mathrm{Hi}-\mathrm{Cr}$ roll after 20th revolution.

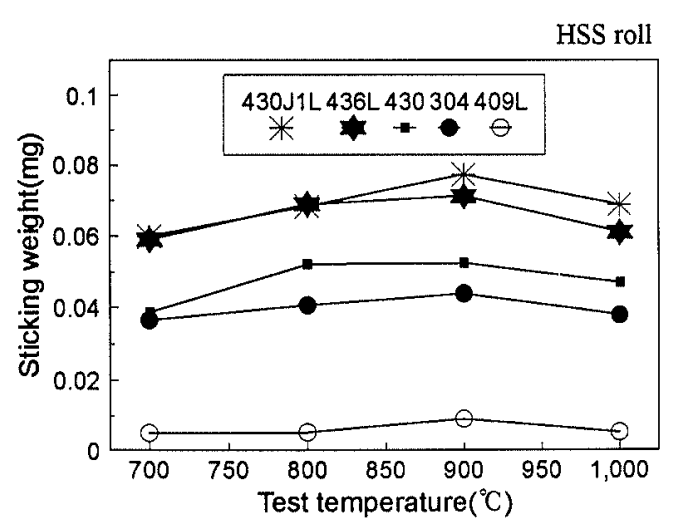

Fig. 8. The effect of temperatures on the changes of the sticking weight on HSS roll after 20th revolution.

of the Hi-Cr roll. Even though the surface roughness was similar in starting condition, more scratches are generated on the surface of the $\mathrm{Hi}-\mathrm{Cr}$ roll during the hot rolling. Conclusively, the $\mathrm{Hi}-\mathrm{Cr}$ roll has a higher number of nucleation sites than the HSS roll.

\subsection{The Effect of Hot Rolling Temperature}

Figure 7 shows the change in sticking weight after 20th revolution of 5 different grade of stainless steels on $\mathrm{Hi}-\mathrm{Cr}$ roll with various hot rolling temperatures. The sticking weight of all steels was increased to $900^{\circ} \mathrm{C}$, then subsequently decreased. A similar tendency was found in the case of the HSS roll (Fig. 8). This indicates that the temperature range having weak sticking resistance was around $900^{\circ} \mathrm{C}$ in all ferritic stainless steels. The austenitic stainless steel 304 also followed this tendency. The sticking occurrence became severe with increase of $\mathrm{Cr}$ weight percent similar to previous results (Figs. 2 and 3).

Previous reports indicate that sticking behavior is attributable to the growth of flake-like particles on the roll surface. Namely, when plastic deformation on the surface layer of stainless steel in the contact arc between roll and material reaches a critical value, a local plastic failure occurs in the surface layer and then, stainless steel particles generated by local failure are transferred to the roll surface. ${ }^{2)}$ It was also reported that the existence of lubricants in the contact arc is effective to prevent the sticking. ${ }^{7}$ From these reports, it is deduced that high tensile strength at high temperature is necessary to

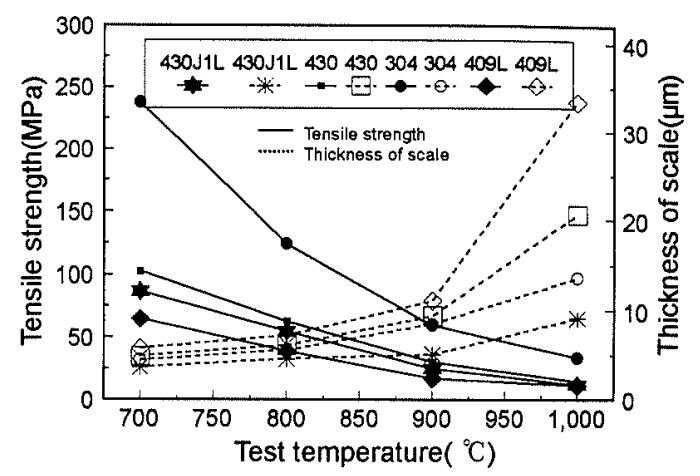

Fig. 9. Changes of tensile strength and scale thickness of stainless steels with temperatures.

prevent the local plastic failure in the surface layer of the stainless steel. The presence of a substantial layer of scale on the rolling material has the role of lubricant and decreases the opportunity for direct contact between the roll and bare metal during hot rolling. Therefore, it is necessary to estimate the high temperature tensile strength and the thickness of the scale of stainless steels, in order to investigate the influence of the scale in the contact arc as well as the high temperature mechanical properties on the sticking behavior. Figure 9 shows the changes of tensile strength and the thickness of scale layer of stainless steels with temperature. The high temperature tensile strength rapidly decreased, and the thickness of scale layer increased with increasing temperature as might be expected. The tensile strength decreased in the order of $304,430,430 \mathrm{~J} 1 \mathrm{~L}$ and $409 \mathrm{~L}$ and the thickness of scale layer decreased in the order of 409L, 430, 304 and $430 \mathrm{~J} 1 \mathrm{~L}$ in all ranges of rolling temperature.

From the above results, it is concluded that the sticking resistance above $900^{\circ} \mathrm{C}$ is expected to be low because of the very low tensile strength of stainless steels, however, thick scale formation above $900^{\circ} \mathrm{C}$ can effectively prevent the sticking despite low tensile strength. On the contrary, in the range below $900^{\circ} \mathrm{C}$, the sticking resistance may be high due to high tensile strength despite a thin scale layer. In consequence, the temperature range near $900^{\circ} \mathrm{C}$ showed the lowest sticking resistance because of the low tensile strength and the thin scale layer. The variation in sticking resistance of the 5 steels may be explained by these conclusions. The austenitic stainless steel 304 , with high tensile strength and thin scale layer, and $409 \mathrm{~L}$ with low tensile strength and thick scale layer, both show good sticking resistance. This indicates that if a specific stainless steel has any one of two properties, high tensile strength and thick scale layer, that steel would show high sticking resistance. But without either of these two properties, that steel would show low sticking resistance. Therefore, 430J1L with low tensile strength and thin scale layer is expected to have the lowest sticking resistance.

Generally, the 400 series stainless steel has a lower sticking resistance than the 300 series. This is because the 400 series do not have a high temperature tensile strength adequate to prevent local plastic failure of the stainless steel surface layer as in the case of the same $\mathrm{Cr}$ weight percent in the 300 series. Particularly, high $\mathrm{Cr}$ ferritic stainless steel with high oxidation resistance is 
expected to show much lower sticking resistance.

\section{Conclusion}

(1) The sticking weight in sticking simulation drastically increased from the first to the 20th revolution, however, after the 20 th, a slight decrease was observed in most of steels.

(2) The sticking weight on the $\mathrm{Hi}-\mathrm{Cr}$ roll was larger than that on the HSS roll. It is due to a lower resistance to abrasion of the $\mathrm{Hi}-\mathrm{Cr}$ roll compared to that of the HSS, that is, the Hi-Cr roll had more nucleation sites of sticking particle per unit area than the HSS roll.

(3) The sticking weight of all investigated steels increased to the rolling temperature $900^{\circ} \mathrm{C}$, then decreased subsequently. The temperature range with weak sticking resistance was around $900^{\circ} \mathrm{C}$.

(4) In the temperature range above $900^{\circ} \mathrm{C}$, the sticking resistance was high because of the thick scale layer despite low tensile strength. On the contrary, in the range below $900^{\circ} \mathrm{C}$, the sticking resistance was also high due to high tensile strength despite a thin scale layer.
(5) The tensile strength decreases in the order of 304 $430,430 \mathrm{~J} 1 \mathrm{~L}$ and $409 \mathrm{~L}$ at all ranges of rolling temperature and the scale thickness decreases in the order of 409L, 430, 304 and 430J1L. Sticking occurred more severely in the order of $409 \mathrm{~L}, 304,430,436 \mathrm{~L}$ and $430 \mathrm{~J} 1 \mathrm{~L}$.

\section{REFERENCES}

1) O. Kato and T. Kawanami: J. Jpn. Soc. Technol. Plast., 28 (1987), 264.

2) O. Kato, S. Uchida and T. Kimuma: Steel Res., 335 (1989), 35.

3) S. Uchida, H. Yamamoto, M. Akata, K. Watanabe and O. Kato: What's New in Roll Technologies of the World, Report of Research Committee on Rolling Roll, ISIJ, Japan, (1995), 183.

4) O. Kato and T. Kawanami: Jpn. Soc. Technol. Plast., 30 (1989), 103.

5) Y. D. Lee, Y. Y. Lee, O. J. Kwon, G. S. Kim and Y. G. Lee: Development of Rolling Technology of 430 Stainless Steel, Report of POSCO Research Inst, unpublished, (1993).

6) J. H. Ryu, K. B. Kang, P. J. Lee and S. G. Shi: Effect of Rolling Conditions on Roll Surface Roughness, Report of POSCO Research Inst., unpublished, (1993).

7) T. Nakanishi: J. Soc. Tribologists Lubricant Eng., 49 (1993), 365. 